\title{
Minerals Matter: Science, Technology, and Society
}

\author{
Barbara L. Dutrow, Dept. of Geology \& Geophysics, E-235 Howe-Russell Geoscience Complex, Louisiana State University, Baton \\ Rouge, Louisiana 70803-4101,USA, dutrow@lsu.edu
}

The expertise of earth scientists is crucial for solving some of today's most pressing challenges, including global warming and the climate crises, natural hazard reduction, water and soil quality, exploration for critical elements for our technological society, and many others.

\section{INTRODUCTION}

Minerals, the solid material comprising planet Earth, are within the intellectual realm of earth scientists but are much more fundamental to science, technology, and society. From the beginnings of humankind, Earth's minerals have been essential for technological advances. Prior to written language, paintings made of mineral pigments adorned caves. The advent of human-produced fire owes its source to two minerals: pyrite and flint. Early Homo species were likely the first mineralogists, separating different minerals into useful tools based on their physical properties to identify, in part, those minerals that perfectly fractured when worked. Utilization of different minerals through melting, smelting, or physical manipulation defines the Ages of Man: Stone, Bronze, Iron, and Technology. Minerals are important basic resources that can inform us about how solid materials work on the atomic level and be modified to humanity's benefit. They serve as templates for technologically advanced materials, necessary to fulfill many societal needs.

The attributes of minerals to science, technology, and society are illustrated by a single mineral, elbaite. Elbaite is a species of the tourmaline supergroup that incorporates nearly the entire periodic table in its structure (Fig. 1). For geoscientists, it embeds unparalleled geologic information when properly interpreted; for technology, it was utilized during WWII as a pressure sensor to monitor underwater explosions due to its piezoelectric properties; and for society, it is a mineral that contains lithium, an element critical to powering modern electronic devices.

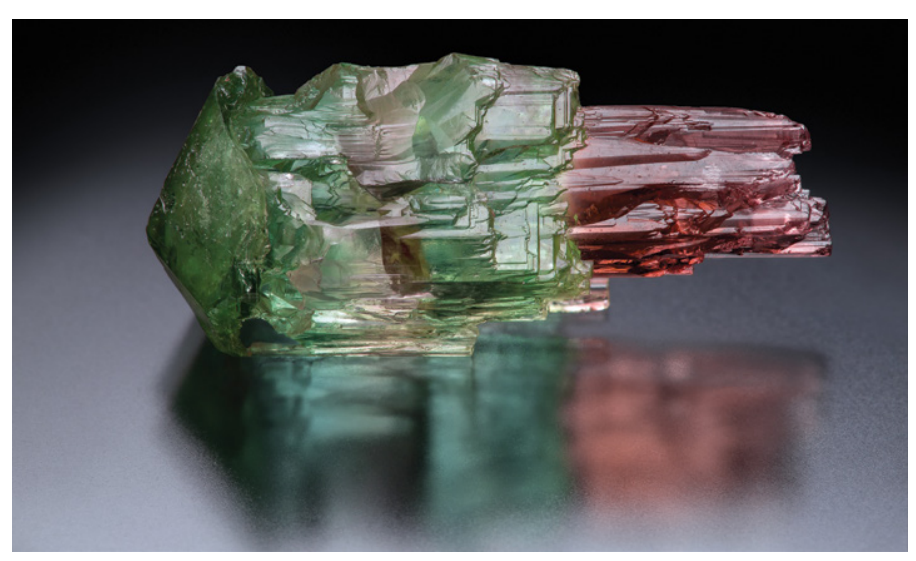

Figure 1. Elbaite crystal, a species of the tourmaline supergroup containing lithium, showing its noncentrosymmetic growth along the long axes (c) which is responsible for its piezoelectric (and pyroelectric) properties, contributing to its utility as a technological material. Color change reflects incorporation of different chemical elements in response to its host environment.
The expansive subject of minerals is familiar to Geological Society of America (GSA) audiences. Several past presidents have spoken on minerals and related topics, presumably beginning with the second president of GSA, James Dwight Dana, in 1890perhaps best known for his enduring textbook The Manual of Mineralogy, first published in 1848 (J.C. Wiley and Sons), and now in its twenty-third edition (Klein and Dutrow, 2007). Why should we continue to care about mineral sciences in the twenty-first century? Because minerals still matter.

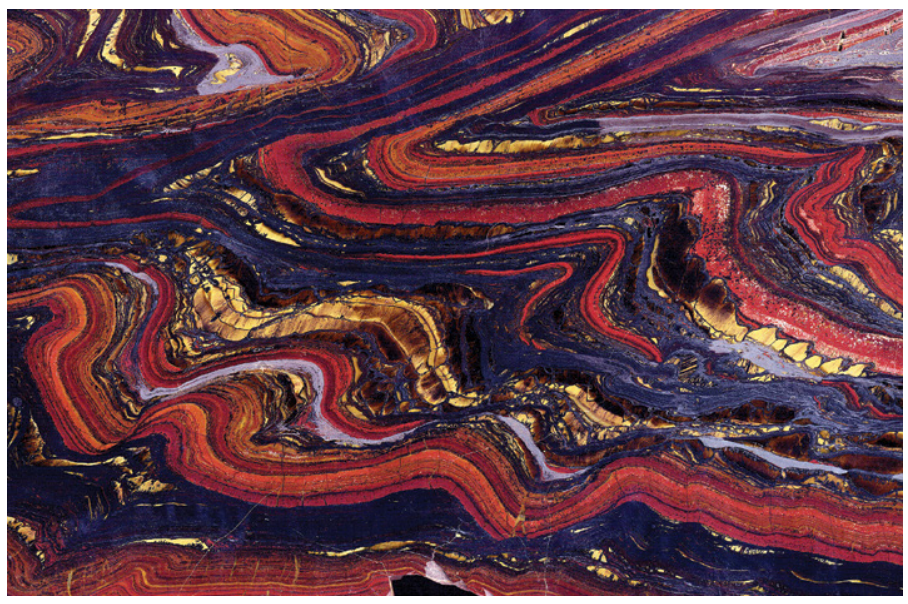

Figure 2. Banded iron formation, a source for iron, a critical component of steel and other manufactured materials. Iron was one of the earliest mined and smelted minerals.

\section{ESSENTIAL BUT UNDERVALUED}

Minerals are vastly underappreciated, and the science of mineralogy is disappearing despite their centrality to society and to the earth sciences. Minerals (continue to) power our lives. They are used in nearly every aspect of our lives, yet do we think of minerals when we walk on planet Earth or answer the cell phone or turn on the lights or start the car? The U.S. Geological Survey (USGS) reports that an average automobile "contains more than a ton of iron and steel, $240 \mathrm{lbs}$ of aluminum, $50 \mathrm{lbs}$ of carbon, $42 \mathrm{lbs}$ of copper, $22 \mathrm{lbs}$ of zinc, and 30 other mineral commodities" (USGS, 2021). These materials do not include the cerium used to polish mirrors or the other components in hybrid or electric vehicles. One primary reason for their underappreciation is that, for the most part, we do not use minerals, per se; we utilize their contents - their chemical constituents (Fig. 2). From aluminum to zinc, the elements extracted from minerals form the basis for advanced materials for our everimproving standard of living.

While mineralogy, or mineral sciences, has been taught largely as an underpinning subject or in support of other earth-science fields (e.g., petrology or geochemistry), its utility to all facets of science, technology, and society elevates this discipline well beyond the geosciences. As industry and governments look to a sustainable

GSA Today, v. 32, no. 2, https://doi.org/10.1130/GSATPrsAdrs21.1. CC-BY-NC. 
future and Environmental Social Governance (ESG) guides business decisions, the earth sciences, specifically mineral sciences, are ever more important to provide foundational information.

Yet, the study of minerals has dwindled, gradually disappearing from the earth-science curriculum, particularly in the U.S. (e.g., Nietzel, 2020; Bierman, 2021). Commonly viewed as "too traditional," mineralogy classes have been reduced in many curricula, compressed into another class (e.g., "earth materials"), or abandoned altogether and expunged from the curriculum, with the concomitant loss of critical expertise. No funding agency supports "mineralogical research" per se. One recent editorial described how difficult it is to find properly trained mineralogists in the U.S. (R. Ewing, personal commun., 2021).

This short article provides a case for mineralogical expertise and implores earth scientists to re-engage with this discipline, because its foundational knowledge and skill sets are integral to earth-science solutions required to tackle some of society's most challenging problems. Additionally, embracing mineralogy in all its forms, by supporting mineralogical research and education, provides fundamental information required to help solve many of Earth's most closely guarded secrets. The criticality of mineralogical knowledge is demonstrated by connecting the mineral sciences across scientific disciplines and into the realm of humankind by providing select examples in science, technology, and society.

To geoscientists, the value of minerals to science is broadly recognized. Resulting from complex planetary processes, minerals are extraordinary archives of Earth's mysteries, allowing scientists to decipher $\sim 4.5$ billion years of embedded history. For example, the minerals in a pallasite meteorite contain clues to the composition, formation conditions, and evolution of the early Solar System, with implications for core-mantle development of Earth. Glacial ice, a mineral, shapes continents, modulates Earth's surface temperatures, and moderates climate variations; it also traps gas bubbles that sample prehistoric $\mathrm{CO}_{2}$ and $\mathrm{CH}_{4}$ levels. Other minerals, such as calcite, can record in their oscillatory zoning patterns the thermal, chemical, and mechanical interactions in complex geosystems. Portions of the biosphere, such as pollen grains, invertebrate exoskeletons, and vertebrate bones and teeth are (bio)minerals. Their former presence, now as fossilized remnants of past life, owe their persistence to mineral replacement (Fig. 3).

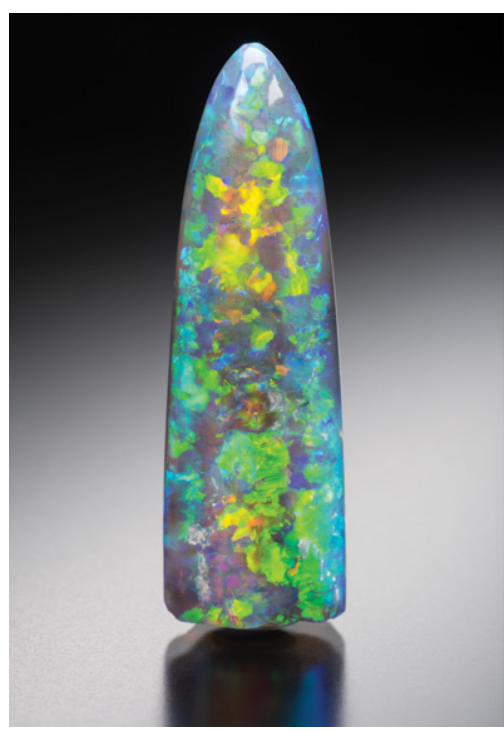

While mineralogy is deeply embedded in most aspects of the earth sciences (Fig. 4), mineralogy bridges disciplinary boundaries and connects earth sciences to other science, technology, engineering, and mathematics (STEM) fields. One such example was recently released by the American Chemical Society in their "reaction" series titled "Are we standing on a quadrillion diamonds?" (ACS, 2021). Chemists are capitalizing on the inspiration and engagement of chemical reactions to make (natural) minerals - clearly trying to take the spotlight from the geosciences. Much of materials science and advanced materials research is built on templates from nature (i.e., minerals). This approach has been largely in the domain of chemists and physicists - yet earth scientists have much to contribute. Because of my mineral-science background, I had the pleasure of serving as a $\mathrm{Ph}$.D. committee member in the chemistry department for a candidate studying the crystal structure of $\mathrm{MoS}_{2}$, which mineral geoscientists know as molybdenite. During the questioning, I asked the candidate if they could identify the shiny, gray, foliated sample of $\mathrm{MoS}_{2}$ I proffered He looked at me quizzically and replied that he had no idea that $\mathrm{MoS}_{2}$ was an actual mineral that occurred naturally on Earth. Clearly, geoscientists with a mineralogical background can inform the STEM community about mutually beneficial subjects. Geoscientists understand complex, heterogeneous, multicomponent, and natural materials over ranges of spatial scales and through time, and are superb analysts, providing natural connections to these disciplines. As such, mineralogy is a translational science, within and outside of the earth sciences.

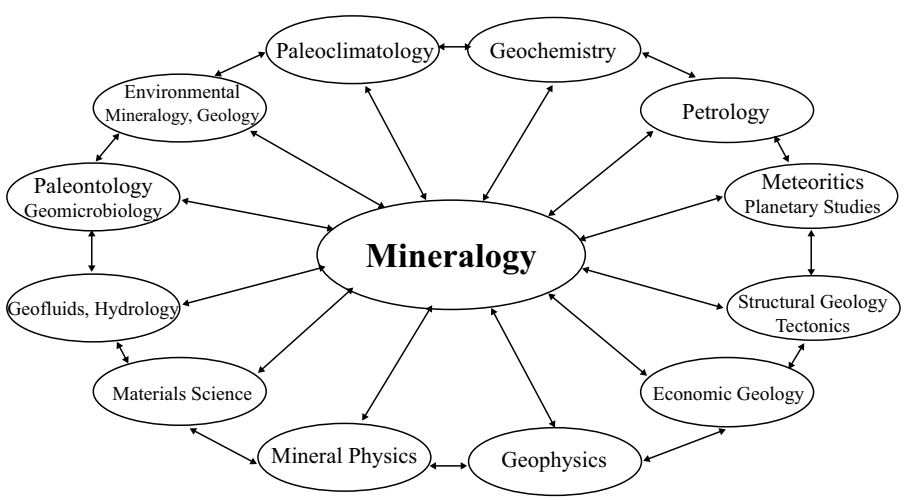

Figure 4. Centrality of mineralogy to earth-science disciplines (modified from Klein and Dutrow, 2007).

\section{MINERALS AND CLIMATE}

Although a myriad of examples is available to demonstrate the value of minerals in technology and society, this article focuses on select mineralogical contributions that will serve as integral components to mitigate the climate crises. These examples include (1) mineral trapping as one method for carbon capture and long-term storage; (2) mineral constituents as essential materials for the energy transformation, highlighting renewable energy and electric vehicles; and (3) minerals as templates for advanced functional materials.

\section{Mineral Trapping}

As the world struggles with the impact of climate change, carbon capture and long-term storage are required for reducing greenhouse gas emissions into the atmosphere, stabilizing and lowering carbon dioxide levels, and ensuring a more robust sustainable climate path 
into the future. Sequestering greenhouse gases can, in part, be achieved by chemical reactions with minerals for one effective approach to carbon sequestration, that is, mineral trapping (e.g., Seifritz, 1990; Oelkers et al., 2008). Magnesium-rich minerals (e.g., olivine, serpentine) react with carbon dioxide to form carbonate minerals that sequester the carbon [e.g., serpentine + carbon dioxide = magnesite + quartz + water $; \mathrm{Mg}_{3} \mathrm{Si}_{2} \mathrm{O}_{5}(\mathrm{OH})_{4}+\mathrm{CO}_{2}=\mathrm{MgCO}_{3}$ $+\mathrm{SiO}_{2}+\mathrm{H}_{2} \mathrm{O}$ ]. Not only is this method geologically rapid-kinetics from both the lab and the field suggest mineral trapping occurs in about two years (Matter et al., 2016) - it results in more permanent storage for carbon than for other geologic mechanisms of trapping (e.g., Oelkers et al., 2008). According to the International Energy Agency (IEA, 2021), there are 20 commercial carbon-capture, utilization, and storage facilities worldwide, with 30 more planned. Earth scientists with an understanding of mineralogy and mineralfluid interactions are essential for this 4-billion-dollar industry.

\section{Critical "Minerals"}

Across the spectrum of renewable "clean" energy technologies, elements obtained largely through the mining of particular minerals, and less commonly the minerals themselves, are critical for implementation. Topping IEA's list of overall critical elements are copper, nickel, chromium, and zinc, along with rare earth elements (REEs), cobalt and lithium for battery storage, and aluminum for electricity networks (IEA, 2021). While the absolute amount varies depending on the energy system, stated governmental policy goals, future planning scenarios, and technological advancements, the ability to secure mineral commodities is the fulcrum in achieving the energy transition away from fossil fuels. This need is crucial for electric vehicle (EV) and battery technologies. REEs, essential in the manufacture of hybrid and electric cars, high-strength magnets for wind turbines, and solar energy panels, are housed in unusual minerals or adsorbed onto their surfaces. The demand for REEs continues to outstrip supply, a situation likely to continue unabated even as new sources are discovered (e.g., monazite sands; Network NewsWire, 2021). Knowledge of mineralogy and mineral systems is needed to locate new resources as demand increases, and to mine, extract, and manufacture materials and their byproducts in responsible ways to minimize environmental damage and human-health impacts.

The global clean energy transitions will have far-reaching consequences for mineral demand over at least the next 20 years. IEA predicts that by 2040 , total mineral demand from clean energy technologies will double in some scenarios and quadruple in others (IEA, 2021). EV and battery storage account for about half of the mineral demand growth, largely for battery materials (lithium, graphite, cobalt, nickel, manganese). To support this increasing technological demand, mineral requirements will grow tenfold to over 30 times over the period to 2040. By weight, graphite, copper, and nickel dominate. The need for lithium has the fastest growth rate, predicted to be more than 40 times current requirements, although new battery technologies may dampen some of this demand (IEA, 2021).

Current battery technology alone will have significant implications for specific elements. A single lithium-ion EV battery pack (CNM532) contains $\sim 8 \mathrm{~kg}$ of lithium, $35 \mathrm{~kg}$ of nickel, $20 \mathrm{~kg}$ of manganese, and $14 \mathrm{~kg}$ of cobalt (Castelvecchi, 2021). With the prediction that in $\sim 15$ years $50 \%$ of the global passenger fleet will be electric (IEA, 2021), hundreds of millions of vehicles will carry batteries that require immense quantities of these of critical materials.
Most lithium derives from minerals, making minerals the lynchpin for progress. Spodumene, $\mathrm{LiAlSi}_{2} \mathrm{O}_{6}$, is the most commonly mined and abundant mineral used for lithium extraction (Table 1, Fig. 5; Bowell et al., 2020). Spodumene contains 3.7 weight percent (wt\%) Li per formula unit. Thus, $214 \mathrm{~kg}$ of pure spodumene are needed for a single car battery! Recently, spodumene was priced at an all-time high of US\$2240/tonne (from western Australia). Worldwide estimates of lithium reserves suggest more than $62 \mathrm{Mt}$ (Bowell et al., 2020). As IEA notes, this massive industrial conversion marks a "shift from a fuel-intensive to a material-intensive energy system" (IEA, 2021). Minerals are the key-they are the reservoirs for our technological future.

Table 1. Major minerals from which lithium is extracted

\begin{tabular}{lcc}
\hline \hline Minerals $^{*}$ & $\begin{array}{c}\mathrm{Li}_{2} \mathrm{O} \\
(w \mathrm{w} \%)\end{array}$ & Chemical formula \\
\hline Spodumene & $6-9$ & $\mathrm{LiAlSi}_{2} \mathrm{O}_{6}$ \\
Petalite & 4.71 & $\mathrm{LiAlSi}_{4} \mathrm{O}_{10}$ \\
Lepidolite & 4.19 & $\mathrm{KLi}_{2} \mathrm{Al}_{\left(\mathrm{Si}_{4} \mathrm{O}_{10}\right)(\mathrm{F}, \mathrm{OH})_{2} \text { to }}$ \\
(series polylithionite-trithionite) & & $\mathrm{KLi}_{1.5} \mathrm{Al}_{1.5}\left(\mathrm{Si}_{3} \mathrm{AlO}_{10}\right)(\mathrm{F}, \mathrm{OH})_{2}$ \\
Amblygonite-Montebrasite & 7.4 & $\mathrm{LiAlPO}_{4} \mathrm{~F} \mathrm{to} \mathrm{LiAlPO}_{4}(\mathrm{OH})$ \\
Eucryptite & 9.7 & $\mathrm{LiAlSiO}_{4}$ \\
Triphylite & 9.47 & $\mathrm{LiFe}^{2+} \mathrm{PO}_{4}$ \\
\hline
\end{tabular}

*Data from Bowell et al. (2020).

\#8 kg Li = $214 \mathrm{~kg}$ spodumene.

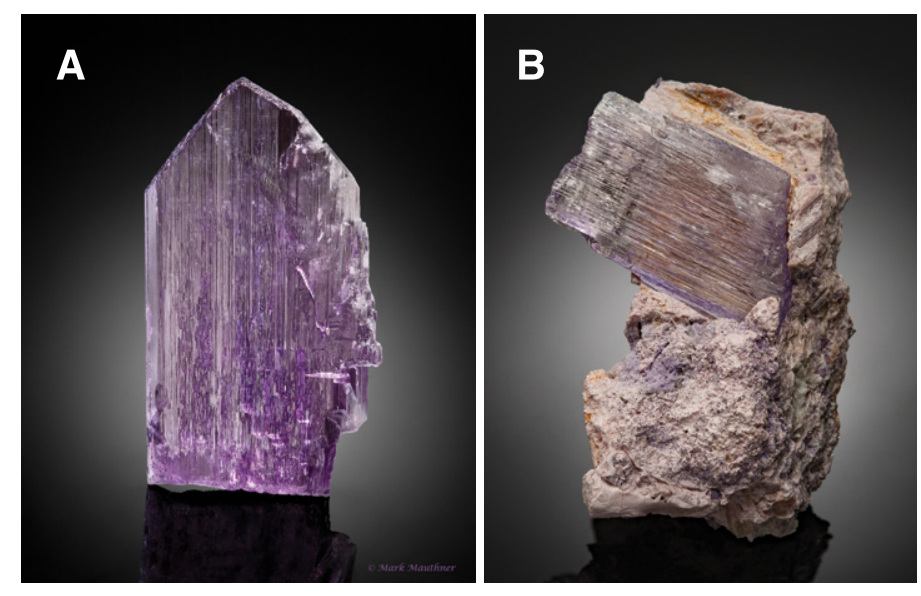

Figure 5. Spodumene, a primary source of lithium. (A) Specimen $28 \times 15.6 \times$ $2.2 \mathrm{~cm}$. Big Kahuna II zone, Oceanview Mine, Pala District, San Diego County, California, USA. Oceanview Mines, LLC, specimen (20120615-01); (B) spodumene in the rock. () Mark Mauthner photos, used with permission.

\section{Minerals as Templates}

Minerals can act as functional templates for advanced materials underlying renewable energy systems. "Wide ranges of additional minerals are used and will be used as the energy landscape is transformed to more renewable, cleaner energies" (Saucier, 2021). Geoscientists with an understanding of minerals, their structures, and compositions, are the "backbone" of the energy transition (Saucier, 2021). Earth scientists are familiar with the perovskite group of minerals. The magnesium-silicate perovskite species, bridgmanite $\left(\mathrm{MgSiO}_{3}\right)$, comprises $\sim 70 \%$ of Earth's lower mantle (Tschauner et al., 2014), which is $\sim 38 \%$ of Earth's total volume. Volumetrically, it is the most abundant mineral in planet Earth. Its flexible crystal structure allows for a wide range of possible 
chemical substituents; it can be engineered to incorporate REEs, making this material extremely useful as a functional material. Their ability to be fabricated in thin films makes perovskites ideal for solar photovoltaic cells (Fig. 6). Perovskite photovoltaics are an emerging technology due to their high efficiencies for converting sunlight to energy. Recent advances to scaling up production of these high-efficiency perovskite solar cell modules have introduced organics into the perovskite precursor-allowing a uniform thin film to be deposited across the entire photovoltaic module area (Huang et al., 2021).

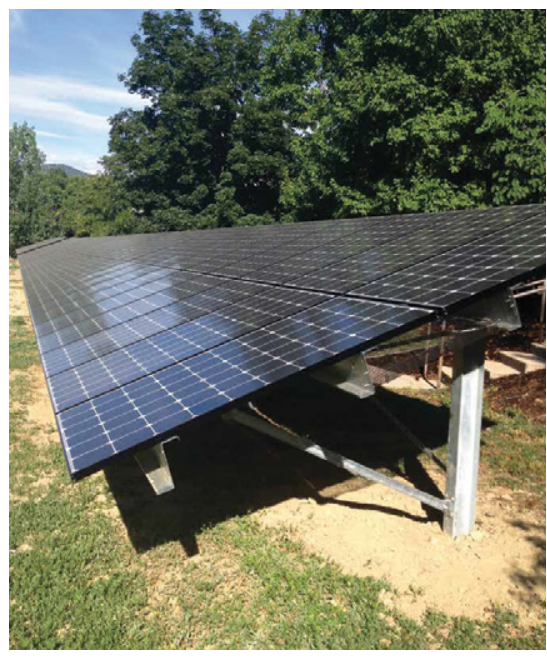

Figure 6. Panel of solar photovoltaic cells at the GSA Headquarters in Boulder, Colorado, USA; used with permission. Perovskite photovoltaics potentially replace the more common silicabased solar cells and have a higher efficiency.

Minerals with a rigid structure and channels that are flexible at different pressures and temperatures are vital to new, improved functional materials. Such mineral properties allow for ionic to superionic mobility, which is critical for developing the next generation of solidstate electrolytes, and power our transition toward a fully renewable future. The feldspathoid analcime is one such mineral, with its channel structure and sodium atoms, and has an onset of super ionic conductivity (D. Palmer, personal commun., 2021; Fig. 7 [see Supplemental Material $\left.^{1}\right]$ ). Zeolite minerals, which also have channel structures and flexible chemistry, have long been used as manufactured materials for molecular sieving and catalysis. For a newer perspective in mineral science, an inside view of a resource needed for transitioning to a renewable energy future is shown in Figure 7 (and see footnote 1). Two crystal representations display the crystal structure showing the position of the ions, the channels, and many of the bonds at an atomic view. One can transform in your mind between the two crystal structure representations, as do our students, to improve the ability to see in 3D. Such knowledge of minerals, their crystallography, and their thermodynamic properties translates through technology and engineering and leads to new advances for materials critical for saving planet Earth in a new, Earth-forward perspective.

\section{DUCT TAPE}

These examples show that mineralogy is like duct tape-knowing how to use it can solve many problems! Minerals can be part of the solution for some of today's stickiest challenges. By the

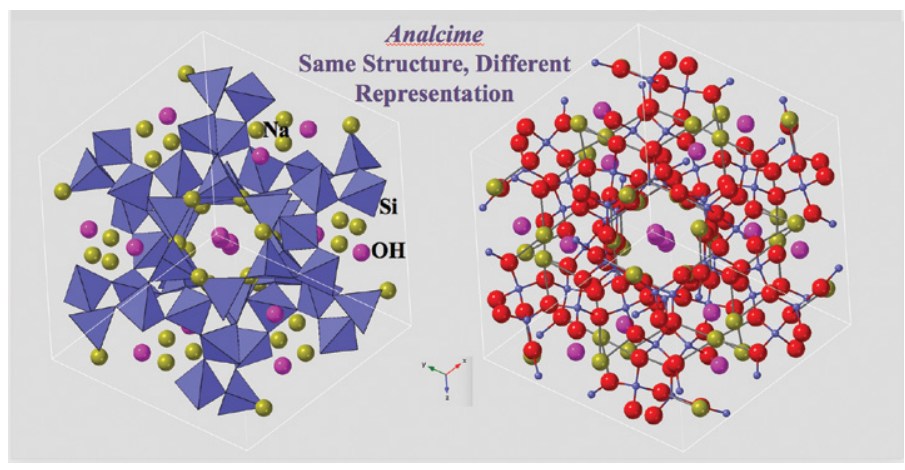

Figure 7. Two representations of the analcime $\left(\mathrm{NaAlSi}_{2} \mathrm{O}_{6} \cdot \mathrm{H}_{2} \mathrm{O}\right.$ ) structure down [111], showing the location of the ions, the channel structure, and several bonds. Polyhedral model (left), ball and stick model (right). (Each representation can be transformed into the other to enhance an ability to see in 3D.) Such minerals have properties for superionic mobility of ions, needed for renewable energy systems. See footnote 1 for a link to the animation.

way, minerals are what make duct tape's stickiness so special. It's stickiness is due to zinc-a chemical element extracted from the mineral sphalerite $(\mathrm{ZnS})$.

\section{MINERALS ARE ESSENTIAL}

Minerals are critically important for powering our future, and mineralogical expertise is essential for unleashing their full potential. Knowing where to explore for specific mineral constituents and how to protect the environment during extraction are paramount to safely securing critical minerals. Understanding minerals, crystal structures, structural constraints, elemental substitutions, and analytical techniques for analyses bridges the earth sciences to other STEM disciplines and leads to computational and experimental advances in new materials, patterned on natural minerals, as resources for transitioning to a cleaner, renewable, energy future. When you turn on the lights, use your cell phone, or start the car, think of the minerals that underlie our technologically rich society and impact our daily lives. "We don't buy minerals, we need their constituents" (USGS, 2021). Today, the vastness of minerals essential to our technological lifestyles cannot be overstated. Let's appreciate minerals in all their scientific enormity.

The time is now for minerals to move to the forefront as the domain of earth sciences and for the geoscientists to embrace this domain by teaching, learning, funding, exploring, and promoting an understanding of minerals for the future of society, as a technological imperative and as a scientific endeavor. Minerals matter!

\section{ACKNOWLEDGMENTS}

My appreciation to Darrell Henry, Nina Rosenberg, and Pamela Kempton for their thoughtful reviews, together with Wendy Bohrson, Dave Mogk, and many other colleagues for unwavering support of this topic. To my many mineralogy students over the years, who asked for more mineralogy classes and encouraged my development of minerals in context, thank you. David Palmer of CrystalMaker (TR) is thanked for sharing his insights on superionic conductivity, for developing the powerful visualization program Crystalmaker, and for making the animation (Fig. 7 [see footnote 1]). Mark Mauthner and Rob Sielecki generously provided photographs.

\footnotetext{
${ }^{1}$ Supplemental Material. Animation flies through the mineral structure of analcime, a mineral with ionic to superionic conductivity. Structure is represented by a ball (showing atoms) and stick (showing bonds) model. The beginning view is a "surface cell" perpendicular to the channel axis looking down $<111>$ to view the pseudo-trigonal representation. Channel axes is 273 Angstroms wide. First image is about 23 times the channel width or 1288 unit cells. Courtesy of David Palmer, CrystalMaker. Go to https://doi.org/10.1130/GSAT.S.17320556 to access the supplemental material; contact editing@geosociety.org with any questions.
} 


\section{REFERENCES CITED}

ACS (American Chemical Society), 2021, Are we standing on a quadrillion tons of diamonds? https://www.acs.org/content/acs/en/pressroom/reactions/ videos/2021/are-we-standing-on-a-quadrillion-tons-of-diamonds.html (accessed 14 Dec. 2021).

Bierman, P., 2021, A department terminated: Science, v. 371, 6527, p. 434, https://doi.org/10.1126/science.371.6527.434.

Bowell, R.J., Lagos, L., de los Hoyos, C.R., and Declercq, J., 2020, Classification and characteristics of natural lithium resources: Elements, v. 16, p. 259-264, https://doi.org/10.2138/gselements.16.4.259.

Castelvecchi, D., 2021, Electric cars: The battery challenge: Nature, v. 596, p. 336-339, https://doi.org/10.1038/d41586-021-02222-1.

Huang, H.-H., and 13 others, 2021, A simple one-step method with wide processing window for high-quality perovskite mini-module fabrication: Joule, v. 5, p. 958-974, https://doi.org/10.1016/j.joule.2021.02.012.

IEA, 2021, The role of critical minerals in clean energy transitions: International Energy Agency, 287 p., https://www.iea.org/reports/the-role-of-critical -minerals-in-clean-energy-transitions (accessed 14 Dec. 2021).

Klein, C., and Dutrow, B., 2007, Manual of Mineral Sciences, 23rd edition: Hoboken, New Jersey, J. Wiley and Sons, 675 p.

Matter, J.M., and 17 others, 2016, Rapid carbon mineralization for permanent disposal of anthropogenic carbon dioxide emissions: Science, v. 352, p. 1312-1314, https://doi.org/10.1126/science.aad8132.

Network NewsWire, 2021, Importance of rare earth elements (REEs) soars as demand increases, 16 Mar. 2021: https://www.prnewswire.com/news-releases/ importance-of-rare-earth-elements-rees-soars-as-demand-increases -301248259.html (accessed 14 Dec. 2021).

Nietzel, M.T., 2020, Major academic cutbacks proposed at the University of Vermont: forbes.com, 3 Dec. 2020, https://www.forbes.com/sites/michaeltnietzel/ 2020/12/03/major-academic-cutbacks-proposed-at-university-of-vermont/ (accessed 20 Dec. 2021).

Oelkers, E.H., Gislason, S.R., and Matter, J., 2008, Mineral carbonation of $\mathrm{CO}_{2}$ : Elements, v. 4, p. 333-337, https://doi.org/10.2113/gselements.4.5.333.

Saucier, H., 2021, Geoscientists Will Be the Backbone of the Energy Transition: Association of American Association of Petroleum Geologists, Aug. 2021, https://explorer.aapg.org/story/articleid/61004/geoscientists-will-be-the -backbone-of-the-energy-transition (accessed 14 Dec. 2021).

Seifritz, W., 1990, $\mathrm{CO}_{2}$ disposal by means of silicates: Nature, v. 345, p. 486, https://doi.org/10.1038/345486b0.

Tschauner, O., Ma, C., Beckett, J.R., Prescher, C., Prakapenka, V.B., and Rossman, G.R., 2014, Discovery of bridgmanite, the most abundant mineral in Earth, in a shocked meteorite: Science, v. 346, no. 6213, p. 1100-1102, https://doi.org/10.1126/science.1259369.

USGS, 2021, Do we take minerals for granted? Overview of the role minerals play in the everyday lives of U.S. residents: https://www.usgs.gov/energy -and-minerals/mineral-resources-program/science/do-we-take-minerals -granted?qt-science_center_objects $=0 \#$ qt-science_center_objects.) (accessed 14 Dec. 2021). 